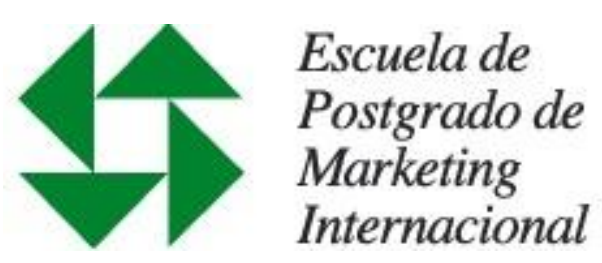

\title{
Propuesta de un plan de marketing para una marca personal.
}

Trabajo Científico libre para la obtención del grado de Magister en Marketing Internacional de la Escuela de Postgrado de Marketing Internacional -Facultad de

Ciencias Económicas

- Universidad Nacional de La Plata -

Presentado por: Luis Guillermo Torres Leaman

Domicilio Argentina: Lima 1125 departamento 13G barrio San Telmo, Buenos Aires, Arg.

Domicilio México: Montes Aconcagua 108 Lomas 2a Sección, San Luis Potosí, México.

Profesor Director de Tesis: Jorge Almada

Fecha de entrega: 12-08-2011 
A mis padres que formaron mi persona

y nuestra marca. 
Como dice un dicho, honor a quien honor merece, primero que nada agradecer a mi profesor, asesor y amigo Jorge Almada por todo su apoyo, motivación y colaboración dentro y fuera de las aulas para poder desempeñar esta tesina, al Dr. Rogelio Simonato y a Liesel por el tiempo brindado, a los profesores de la EPMI por sus conocimientos y a mis compañeros por su entrega.

En un segundo punto y no menos importante a Jesús Torres y Nancy Leaman por ser mi fuerza y sostén este tiempo fuera de casa, a Giovanni Ortega por los consejos durante la elaboración de esta tesina, a Rubí Díaz por ser parte de este proyecto, por su apoyo y compañía cuando las ideas no alcanzaban una frase y necesité una plática y un tiempo de relax, y a Blanca Medina Fonseca por el tiempo en la organización de las ideas.

A todos ustedes, gracias por hacer esto posible.

Guillermo Torres

$12 / 08 / 2001$ 


\section{Prólogo}

En esta tesina se identifican los elementos de un plan de marketing dedicado hacia las personas, a partir de la identidad y perfil de éstas se explica el cómo se definen las herramientas a usar para lograr cierto liderazgo dentro del entorno donde se desarrolle, mediante el desarrollo de una "marca personal" que además de brindar posicionamiento, se enfoca en el desarrollo personal y laboral a largo plazo.

En la mayoría de los escritos se ve que el desarrollo de un plan de marketing va enfocado en productos y en menor amplitud a servicios, sin embargo, son pocos los que se enfocan a las personas, por lo que en esta tesina busca enfocar las herramientas de un plan de marketing para el desarrollo personal de los individuos con un enfoque multidisciplinario.

\section{Objetivo.}

Plantear los lineamientos y necesidades básicos para transformar la identidad de una persona en una "marca personal".

\section{Objetivos específicos.}

- Identificar los atributos personales que puedan formar parte del plan de Marketing Personal.

- Seleccionar las herramientas para un plan de marketing dirigido hacia las personas.

- Elaborar una estrategia a largo plazo para lograr los objetivos personales.

\section{Metodología.}

- Investigación descriptiva, en su mayoría documental de conceptos básicos de marketing, e historia del mismo.

- Fuentes primarias obtenidas de experiencias en el campo laboral, en aéreas de relaciones públicas, asesorías de imagen, campañas políticas, universidades y oficinas de gobierno. 
- Entrevistas con psicólogos, marketineros y artistas para tener otros enfoques en temas de personalidad, identidad, marcas, etc.

- Fuentes secundarias obtenidas de autores de la teoría de marketing y especialistas dedicados al marketing de las personas.

- Investigación aplicada en una artista dedicada a la danza. 


\section{Índice}

Marco Teórico...................................................... 7

Tendencias del Marketing .................................... 11

Marketing Personal.............................................. 15

Plan de Marketing ............................................ 25

Caso de aplicación............................................. 32

Conclusiones.............................................. 39 


\section{Marco Teórico}

Todos los días estamos en constante vinculación con el marketing; ya sean empresas que muestran su producto, personas con marcas escogidas, bienes de uso diario que se han posicionado tan fuertemente en la mente que son parte de nuestras vidas, pero son pocos los que desarrollan una marca a partir de su persona buscando un crecimiento personal, en los ámbitos laborales, sociales y personales.

A esto lo llamaremos "marketing personal" y es "el concepto que cada persona es capaz de proyectar de sí misma al resto de la sociedad, a través de las acciones de su vida, que son tomadas de su propio plan estratégico personal, CREANDO VALOR al hacer felices a los demás"1, "este concepto implica más que, un enfoque comercial, herramientas para conseguir un nuevo trabajo, lograr un cambio laboral, provee un enfoque holístico enriquecido a través de la posibilidad de transformarnos y ser el mejor Ser que podamos llegar a ser, para sentirnos en armonía. A través de alcanzar esa armonía interior, nuestros resultados, en cualquier ámbito, ya sea profesional, laboral ó personal serán diferentes."2.

Como un fin del marketing personal se contempla la creación de una "marca personal" para lograr los objetivos individuales en las diversas actividades multidisciplinarias en las que la persona esté involucrada, así mediante el uso de un plan de marketing se crea el inicio de la estrategia que culminará en el trabajo que diferencie al individuo en su ámbito personal y laboral ante el entorno que lo rodea.

Antes de empezar este proceso de diferenciación lo que tenemos que saber es ¿Qué es una marca? Es el "nombre, término, signo, símbolo, diseño o combinación de éstos, que sirven para identificar los bienes o servicios de un

\footnotetext{
${ }^{1}$ Ricardo Alcázar, Marketing Personal ( Aptitus El Blog de Recursos Humanos,15 de mayo de 2010, http://blog.aptitus.pe/bienestar-personal-y-profesional/744/)

2 Sonia Grotz, Marketing Personal... ¿Para qué? (Negocios - IDEA, http://www.ideared.org/contenido/289/marketing)
} 
vendedor o grupo de vendedores y para diferenciarlos de la competencia"3 . "La marca es una gran máquina de producir significados, construye mundos posibles y les da un decorado atractivo.. es un nombre y como tal un ente simbólico que permite que el producto le hable al consumidor"4, entonces una marca personal será el nombre con que se dará a conocer la persona ante el ambiente donde se desarrolle, ya sea usando su nombre y apellido como en algún bufete de abogados, o alguna consultora, candidato político, profesional, etc., o manejando algún sobrenombre como algunos deportistas o artistas, pero cada uno de ellos basan esa marca en su personalidad e identidad.

Definimos personalidad en un "conjunto de máscaras sociales convencionales y habilidades profesionales que utilizamos como medida de valor de una persona", como una "estructura con características propias, donde la forma en que las cosas se mantiene unidas está siempre desarrollándose en uno u otro elemento y cambiando. Además, este atributo humano tendría que ver con lo que nos mueve a actuar, y el cómo, dónde y por qué hacerlo, con elementos (mentales, físicos e incluso sociales) entrelazados y que además se caracterizarían por su delimitación." ${ }^{6}$ Es decir nos plantean la personalidad como un conjunto de experiencias físicas, mentales, sociales, familiares que desarrolla la actitud y forma de comportamiento de un individuo, pero que puede estar en constante cambio según las nuevas experiencias que se vayan incorporando en la vida de cada persona.

La importancia de ésto se debe a que la personalidad forma gran parte del comportamiento hacia los demás y es fundamental en la creación de identidad. Esta relación la podemos ver plasmada de la siguiente manera:

\footnotetext{
${ }^{3}$ Philip Kotler, Kevin Lane Keller, Dirección de Marketing (Pearson Educación, México 2006, pág. G5 glosario)

${ }_{5}^{4}$ Alberto L. Wilensky, La promesa de la marca (Grupo editorial Temas, 1998, pág. 36)

${ }^{5}$ Debashis Chatterjee, El liderazgo consciente, un peregrinaje hacia el autocontrol (Ed. Granica 2001).

${ }^{6}$ Lorena Antiguay, Ensayo de El concepto de personalidad:Allport y Shelldon (Universidad de Santiago de Chile 2002).
} 


\section{Caracteristicas emocionales asociadas a la personalidad}

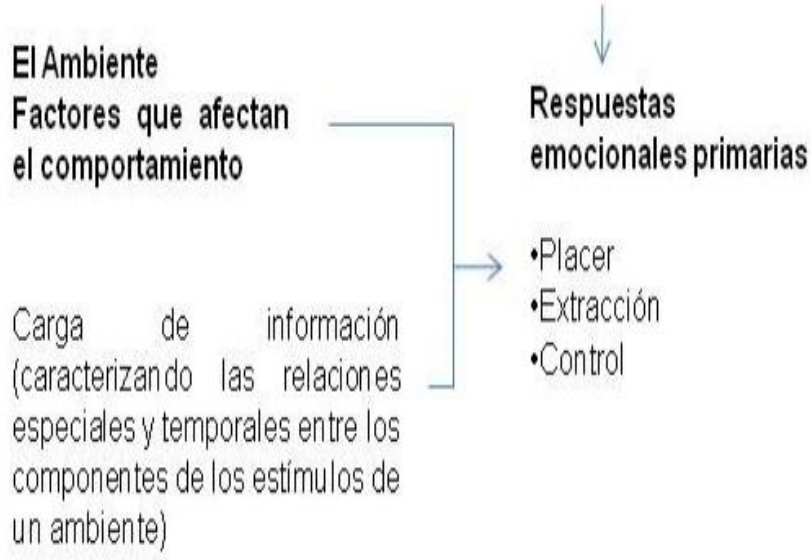

Respuestas en el comportamiento

acercamiento - alejamiento

$\rightarrow$ (incluye acercamiento físico, exploración, afiliación, presentación u otras comunicaciones verbales o no verbales)

\section{(Interacción social)}

Placer-Desagrado estado de animo, sonrisa, risa positivavs negativa, preferencias, gustos, aprovechamiento 0 evitación.

Excitación: desde el sueño, hasta el entusiasmo frenético (acto informe verbal que mide el estado de animo), actividades vocales, faciales, expresión, discurso (Tiempo y Volumen).

Control: Sentimientos de libertad, sin restricciones para actuar, sentirse en su propio territorio.

\section{"An approach to environmental Psychology", por Mehrabian y Russell, 1974P. 8}

En este cuadro vemos un ejemplo de cómo la personalidad influye en el comportar de los individuos, y en la respuesta del comportamiento de los demás, y con estos estímulos de personalidad se puede crear una identidad, este concepto "implica por lo menos los siguientes elementos: (1) la permanencia en el tiempo de un sujeto de acción (2) concebido como una unidad con límites (3) que lo distinguen de todos los demás sujetos, (4) aunque también se requiere el reconocimiento de estos últimos y su función es marcar fronteras entre un nosotros y los "otros", y no se ve de qué otra manera podríamos diferenciarnos de los demás”, que es el resultado de un proceso complejo, donde lo que se busca es ser único, y es la forma en que se verá al individuo en su exterior, es decir en el entorno donde se

\footnotetext{
${ }_{8}^{7}$ Mehrabian y Russell, An approach to environmental Psychology(1974 P8).

8 Gilberto Giménez, La Cultura como Identidad y la Identidad como Cultura. (SIC. CONACULTA. México, http://www.oei.es/cultura/diversidad_cultural.htm).
} 
esté desarrollando, en otras palabras diferenciarse y diferenciar así su marca personal. Esta diferenciación logra crear un posicionamiento de cada persona, este es el ranking mental que ocupa una marca, en un determinado consumidor “implica decidir cuál será el entorno activo que la persona pretende ocupar". Es decir, el posicionamiento se dará conforme más distinto y diferente puedo ser visto por el consumidor o cliente; "reza un anónimo, "Dime porque eres distinto a los demás y te amaré toda la vida"."10, y es precisamente el ser único lo que se necesita para mantener y obtener más clientes.

Para lograr este posicionamiento usamos distintas herramientas; en esta tesina la finalizaremos con los lineamientos y necesidades básicas para transformar la identidad de una persona en una marca personal, mediante un plan de Marketing, este "es un documento escrito que resume lo que se conoce sobre el mercado e indica cómo es que la empresa pretende alcanzar sus objetivos" ${ }^{\prime 1}$, este nos sirve para tener una planeación de las diversas actividades que hacer y aprovechar el poco tiempo para cumplirlas, el fin del plan de marketing es el cumplir los objetivos propuestos.

Así se tendrá al final de esta tesina una propuesta de cómo hacer un plan de marketing dirigido hacia las personas, que atributos personales resaltar y que estrategia utilizar para lograr los objetivos personales.

\footnotetext{
${ }^{9}$ Gustavo Martinez Pandiani, Marketing Político campañas, medios y estrategias electorales. (Ugerman Editor $4^{\mathrm{a}}$ edición 2007).

${ }^{10}$ Luis Enrique Rojas Rojas, Posicionamiento de marcas (ITESM, 17 de agosto de 2005, México)

${ }^{11}$ Marian Burk Wood, The Marketing Plan: A handbook (Upper Saddle River, NJ Prentice Hall, 2003, p.B1)
} 


\section{Tendencias de Marketing}

Así como lo decía constantemente el ex presidente de GE (General Electric) Jack Welch, "Renovarse o morir", para que el marketing haya podido seguir como un importante tema de estudio se debe a la capacidad que ha tenido esta disciplina para moldearse a lo largo de los años. En cualquier parte del mundo las sociedades van transformándose; cambia su entorno, su cultura, su gente, lo que provoca que el consumo, el deseo, las decisiones, las metas y los objetivos de las personas también vayan modificándose y ésto aunado con la creciente innovación de productos tecnológicos que acelera el proceso, hace que todo este cambio sea exponencial.

Comencemos con algo de historia del marketing, no hablaremos en esta tesina del inicio básico donde comienza el comercio entre los pueblos y la diferenciación de los productos que cada uno de ellos usaba para cumplir las necesidades básicas de alimentación, agricultura, caza, etc., iremos más adelante a finales de los cincuentas donde el marketing era considerado como parte de la distribución de las empresas, cuando se consideraba como "el conjunto de esfuerzos que efectúan transferencia de la propiedad de bienes y se ocupan de su distribución física" ${ }^{21}$ y su manejo publicitario generalmente era uno a uno o de boca a boca, las decisiones para los consumidores eran sencillas respecto a los productos $\mathrm{y}$ servicios que se obtenían pero esto no iba a durar demasiado.

En los años sesenta comienza el concepto de marketing masivo, y su primer definición general como "la realización de actividades empresariales que dirigen el flujo de bienes y servicios desde el productor al consumidor o usuario"13 donde se empieza a buscar no solo la creación y distribución del producto, sino el satisfacer necesidades de los consumidores, por lo que se inicia a usar mayormente el concepto de las 4 p's y la teoría del comportamiento del consumidor. Pero esto no se dio por obra de magia, se dio por el cambio

\footnotetext{
${ }^{12}$ Traducción de F.E.Clark de Bartels, 1988, pp. 149-150,(sustraído de Amadeo Pérez, Historia y teoría del Marketing, http://amadeo.obolog.com/historia-teoria-marketing-23017)

${ }^{13}$ AMA, Committee on Definitions, 1960, p. 15.
} 
sociocultural y tecnológico que estaba en esta década, el crecimiento de los medios de comunicación masivos, como la televisión y la radio fomentan el posicionamiento de los productos y marcas, esta innovación fue tan grande que el consumo masivo logró segmentar el mercado.

Durante los años setenta surge el marketing de segmentación, esto se da por la necesidad de los consumidores de sentirse únicos, sentirse diferentes, posicionarse ante los demás, así mismo es un punto primordial para la creación en un futuro del marketing personal, y de la planeación estratégica para poder satisfacer las necesidades diferenciadas de cada consumidor, esta diferenciación por segmentos abre otras vertientes como es el marketing de servicios que "John Rathmell los definió como actos, obras, ejecuciones o esfuerzos"14 y el marketing social que es el "que lleva a cabo una organización sin fines de lucro o una institución gubernamental para promover una causa"15.

A partir de los años ochenta comienza en el mundo una tendencia hacia la globalización, movilidad e individualidad lo que produce otra variación del consumo y por ende del marketing. Se crea a través de la Asociación Americana de Marketing (AMA American Marketing Association), una nueva definición como "el proceso de planificación y ejecución de la concepción, precio, comunicación y distribución de ideas, productos, y servicios, para crear intercambios que satisfagan a los individuos y a los objetivos de la organización",16.

En este nuevo concepto y esta tendencia individual se segmenta aun más el consumo formando nichos de mercado, que a su vez con este boom de consumo y de globalización permite nuevas tendencias como el marketing interno que son las “actividades internas dirigidas a los empleados para capacitarlos, motivarlos"17, el

\footnotetext{
${ }^{14}$ Christopher Lovelock y Jochen Wirtz, Marketing de Servicios (Pearson Educación, México 2009, sexta edición, pág. 14)

${ }^{15}$ Philip Kotler y Kevin Lane Keller, Dirección de Marketing (Pearson Educación, México 2006, duodécima edición, pág. G5)

${ }^{16}$ AMA, Committee on Definitions, 1985

${ }^{17}$ Christopher Lovelock y Jochen Wirtz, Marketing de Servicios (Pearson Educación, México 2009, sexta edición, pág. 630)
} 
marketing directo "empleando canales directos para llegar a los consumidores y entregarles bienes y servicios sin necesidad de intermediarios" ${ }^{\prime 18}$, mega marketing como la "coordinación estratégica de capacidades económicas, psicológicas, políticas y de relaciones públicas con el fin de obtener la cooperación de una serie de terceros para entrar a un mercado determinado u operar en él"19 y el marketing relacional que busca "desarrollar vínculos redituables a largo plazo entre una organización y sus clientes para beneficio de ambas partes" ${ }^{20}$, como podemos ver empiezan a crearse tendencias muy centradas en el individualismo, en buscar al cliente y hacer el consumo lo más sencillo y diferenciado para él, creando esa cercanía y decisión individual que buscaría posicionar de mayor manera algún bien o servicio.

El individualismo de la década de los ochenta tiene su auge con la aparición de la informática en los noventa, esta herramienta permite personalizar el marketing y buscar nuevos nichos de mercado, que ayuda a diferenciar aun más a los clientes, esto aunado a la época histórica de globalización-capitalismo en la que se vivía permite desarrollar nuevas formas de consumo.

Durante estas décadas se fue quedando atrás el concepto de marketing igual a producción, o marketing igual a publicidad y se toma como un todo; según la AMA en el 2004 lo define como "una función de la organización y un conjunto de procesos dirigidos a crear, comunicar y distribuir valor a los clientes y a dirigir las relaciones con los clientes de forma que beneficie a la organización y sus públicos de interés" ${ }^{21}$, surgen nuevas tendencias como el uso del internet, la comunicación inmediata y masiva, las redes sociales y claro el consumismo y materialismo moderno, existe una guerra publicitaria donde diariamente se bombardea el

\footnotetext{
${ }^{18}$ Philip Kotler y Kevin Lane Keller, Dirección de Marketing (Pearson Educación, México 2006, duodécima edición, pág. G5)

${ }^{19}$ Philip Kotler y Kevin Lane Keller, Dirección de Marketing (Pearson Educación, México 2006, duodécima edición, pág. G5)

${ }^{20}$ Christopher Lovelock y Jochen Wirtz, Marketing de Servicios (Pearson Educación, México 2009, sexta edición, pág. 629)

21 AMA, Committee on Definitions, 2004, (American Marketing Association Board of Directors)(Marketing is an organizational function and a set of processes for creating, communicating, and delivering value to customers and for managing customer relationships in ways that benefit the organization and its stakeholders)
} 
mercado de tal forma que los productos y marcas llegan a perder credibilidad, comienzan tendencias contradictorias en algunas partes del mundo como la "fast food vs slow food \& wellness", lo que hace más difícil la puesta en marcha de estrategias de marketing, aún con esta desacreditación en cuanto a productos y marcas puede verse que el marketing ya estaba presente en diferentes sectores como, bienes y servicios, eventos, turismo, información e ideas, derechos, organizaciones y personas, donde antes no estaba presente.

Pasado el análisis de las décadas anteriores se logra distinguir la tendencia del ser humano hacia la individualidad y la diferenciación, busca poder tanto tener cosas únicas como ser único en lo que él desarrolla, basándose en esta tendencia surge el marketing personal, en donde cada individuo tiene la oportunidad de crear su propia marca, dejar a un lado solamente la venta de sus servicios o de sus productos y busca un desarrollo general, íntegro, un crecimiento personal que le permita cumplir con sus objetivos desde su persona, y crear un posicionamiento en su entorno que no acabe con un intercambio de bienes o servicios sino con un proyecto de vida a largo plazo. 


\section{Marketing personal}

Para empezar a describir que es el marketing personal y sus aplicaciones recordemos ¿cuántas veces hemos estado en una etapa de nuestra vida donde no estamos saludables, emocional, laboral, social y personalmente "bien”?, y ¿a qué se refiere ese "bien”?, ¿cuándo ocurre esto?, generalmente esto se debe a alguna insatisfacción con el lugar de trabajo, la familia, nuestra persona, nuestro desempeño, o por tener alguna necesidad que no se ha cumplido.

Abraham Maslow mediante la pirámide de necesidades, en su teoría de la jerarquía de necesidades humanas, dibujó el orden de cumplimiento de estas, la cual consistente en una pirámide que contiene las necesidades humanas, psicológicas y físicas en diferentes escalones que tienen que ir cumpliéndose para llegar a un punto de autorrealización y armonía con uno mismo y son:

- Necesidades básicas o fisiológicas.

- Necesidades de seguridad y protección.

- Necesidad de afiliación.

- Necesidad de reconocimiento.

- Necesidad de autorrealización. ${ }^{22}$

${ }^{22}$ Abraham Maslow . The Developing Person through the Life Span. 1983. Pg. 44. 


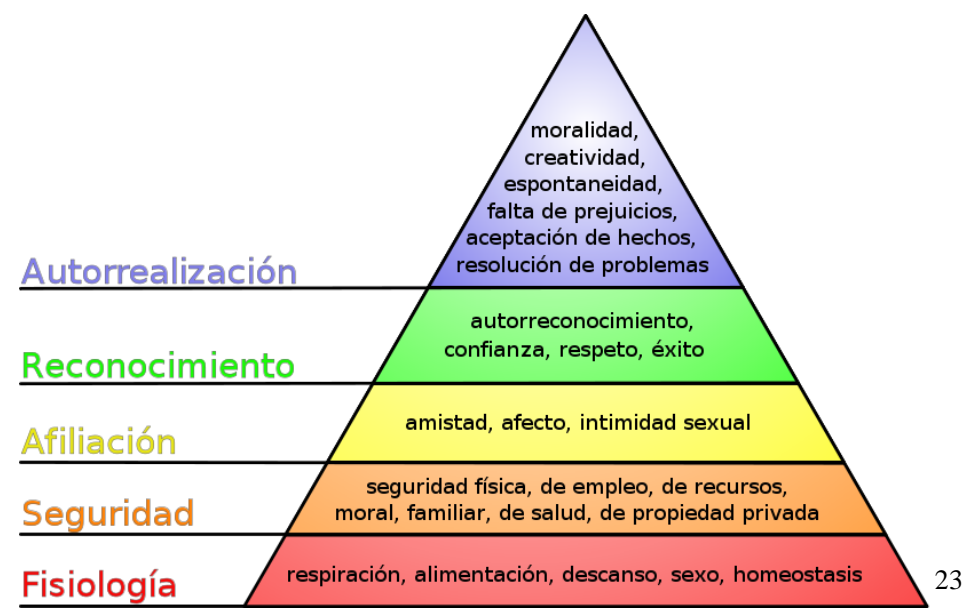

Se puede observar en la pirámide de Maslow que una vez satisfechas las necesidades básicas, se desarrollan otras necesidades y deseos superiores, y se van satisfaciendo hasta llegar a lo que llamó la autorrealización, sin embargo pasa por la necesidad de reconocimiento ahí es donde se enfocará el esfuerzo del marketing personal ya que en esta etapa se incluye el éxito y el status, así como la percepción del individuo hacia sí mismo y el estima de los demás hacia el individuo.

En esta etapa es donde puede haber un cambio, ya que se busca el último paso para realizarse, y donde al tener esta evolución en las necesidades de las personas, se tratará de obtener una forma en que día a día se pueda ser mejor en todos los aspectos, teniendo cambios intermedios, para lograr que la persona pueda dar su mejor desempeño.

Entonces podemos decir que el marketing personal "Es un sistema total de actividades ideado para planear productos en este caso personas, satisfactores de necesidades y deseos, desarrollar estrategias comerciales para saber a qué mercado laboral se dirigen, el análisis personal de cada persona a lo largo de su vida, posicionamiento en donde van a querer ubicarse en la mente del empleador y de sus conocidos, estrategias del marketing mix, es decir la asignación de sueldos a negociar, promoción o comunicación integral ,en este caso C.V. , carta de presentación, entrevistas tarjetas personales, red de contactos, participaciones

\footnotetext{
${ }^{23}$ Abraham Maslow, Una teoría sobre la motivación humana (pirámide de Maslow o teoría de las jerarquías de las necesidades humanas, 1943).
} 
sociales, académicas etc. y promoverlos y como llegar a los mercados meta, a fin de lograr los objetivos personales." 24

Donde el resultado del uso de las 4 p's en el marketing personal, no es solo saber venderse en un mercado, o ser vendedor de algo en algún lugar, es ser mejores personas desde un punto el vista de un producto premium, es el poder descubrirse uno mismo y poder realizar un proyecto de vida a partir de los objetivos que se quieren lograr, teniendo un especial cuidado por la imagen, acciones que realizamos, y por tener en claro algunas preguntas básicas como ¿Dónde estamos?, ¿A dónde vamos? Y ¿A dónde queremos ir? Teniendo estas respuestas claras, el camino al cumplimiento de los objetivos personales será más sencillo.

Desde el punto de vista de las 4 p's se puede comparar a la persona con un producto pero aunque veamos a la persona como un producto existen diferencias entre el marketing comercial y el marketing personal que tenemos que tomar en cuenta para poder identificar las particularidades que necesitaremos para explotar al máximo los atributos personales del individuo.

En el siguiente cuadro se muestran las principales diferencias que tenemos que tomar en cuenta para el desarrollo del marketing de una persona y son las bases para la elaboración de estrategias de creación de marca, posicionamiento y liderazgo.

\footnotetext{
${ }^{24}$ Ing. J. Luis Linares V. P, Concepto de marketing personal (Blog Marketeando
} http://www.marketeando.com/2009/09/concepto-marketing-personal.html) 


\begin{tabular}{|c|c|c|}
\hline \multicolumn{3}{|c|}{$\begin{array}{l}\text { DIFERENCIAS ENTRE MARKETING COMERCIAL Y MARKETING } \\
\text { PERSONAL }\end{array}$} \\
\hline & COMERCIAL & PERSONAL \\
\hline $\begin{array}{l}\text { Lógica del } \\
\text { mercado }\end{array}$ & Satisfacer necesidades & $\begin{array}{l}\text { Satisfacer necesidades a través } \\
\text { de la elección de alternativas }\end{array}$ \\
\hline Productos & Bienes y Servicios & Personas \\
\hline $\begin{array}{l}\text { Valor } \\
\text { Simbólico }\end{array}$ & Consumo/Gustos/Preferencias & $\begin{array}{l}\text { Ideales/Empatía/Valores/ } \\
\text { Profesionalismo }\end{array}$ \\
\hline Demandantes & Consumidor & Seguidores//Fans/Clientes \\
\hline Oferentes & Empresas & Individuos \\
\hline Comunicación & Publicidad/Medios & Publicidad/Medios/Propaganda \\
\hline
\end{tabular}

Interpretando el cuadro anterior:

Primero tenemos que tomar en cuenta la lógica del mercado; en el marketing de consumo lo que se busca es satisfacer las necesidades con bienes y servicios, en cambio en el marketing personal busca esa satisfacción de necesidades a través de una elección de alternativas que puede dar una persona, por ejemplo un cliente en búsqueda de un dentista para un dolor de muela no buscará el primero que encuentre sino que tendrá una elección de alternativas entre varias propuestas y se quedará con quien le resulte más cómodo y con mejores resultados, sin importar si se considera un producto premium o un commodity o si realmente es el que da mejores resultados, simplemente es quien forma esa relación de satisfacción y en el momento de la elección para el cliente, el dentista se convierte en un producto premium para él. Y vemos como el valor simbólico entre cada uno cambia ya que lo que le da la importancia al dentista no son los gustos y preferencias del cliente sino la empatía, valores y profesionalismo que ve en el dentista.

\footnotetext{
${ }^{25}$ Adaptación de gráfico de Gustavo Martínez Pandiami, Marketing Político Campañas, Medios y Estrategias Electorales (Ungerman Editor $4^{\text {a }}$ edición 2007, p.40)
} 
Ya que tomamos en cuenta la diferencia entre producto y persona, y que sabemos que la tendencia que se vive hoy en día es una economía de la reputación podemos pasar a una parte central en la elaboración del marketing personal y es el tener una marca personal, cómo crear una marca personal y por qué es importante tener una marca personal para "no ser uno más, si no vos, un ser único que nunca ha existido, ni existirá. Si puedo construir mi marca personal, si puedo en el ámbito laboral ó personal generar un valor único, seguramente no será fácil reemplazarme."26

Como dijo Florentino Pérez presidente del FC Real Madrid hablando de Cristiano Ronaldo "pues hombre... lo pagamos porque lo vale. Lo pagamos porque devuelve ese dinero, y lo devuelve con intereses. O sea, jugadores de esa categoría hacen que nuestros sponsors, que nuestros contratos de televisión, nuestros contratos de ropa deportiva, aumenten de una manera espectacular",27

Una marca es "un nombre y por lo tanto un signo que designa, es una clase de nombre propio que, a su vez, expresa una específica personalidad" ${ }^{28}$, que se da por el "sentido de individualidad y de individuación propio del ser humano. Existe una necesidad interna de reconocimiento social e individual, que nos distingan frente a los otros, que nos reconozcan como individuos diferentes. Es una forma de trascender, de escapar de la noción de hombre-masa"29

Entonces conociendo como es la marca y el por qué surge, podemos desarrollar el cómo crear una marca, recordando que la marca personal será un identificador a lo largo de toda la vida ya que es más difícil cambiar la marca personal y que vuelva a ser aceptada, que simplemente dar un cambio en la vida llevando esa marca con uno mismo y adecuándola al nuevo entorno donde se desenvuelva.

\footnotetext{
26 Sonia Grotz, Marketing Personal... ¿Para qué? (Negocios - IDEA, http://www.ideared.org/contenido/289/marketing)

${ }^{27}$ Entrevista con Florentino Pérez, Presidente del FC Real Madrid. (2009).

${ }^{28}$ Alberto L. Wilensky, La promesa de la marca (Grupo editorial Temas, 1998, pág. 67)

${ }^{29}$ Manuel Scheneer, Tu eres tu propia marca, Marketing personal para un profesional (Editorial Norma, Bogotá, 2005 pág. 57
} 
¿Qué debe tener una marca?, según Wilensky en su libro de La promesa de la marca, estas tienen que contener distintos elementos: $:^{30}$

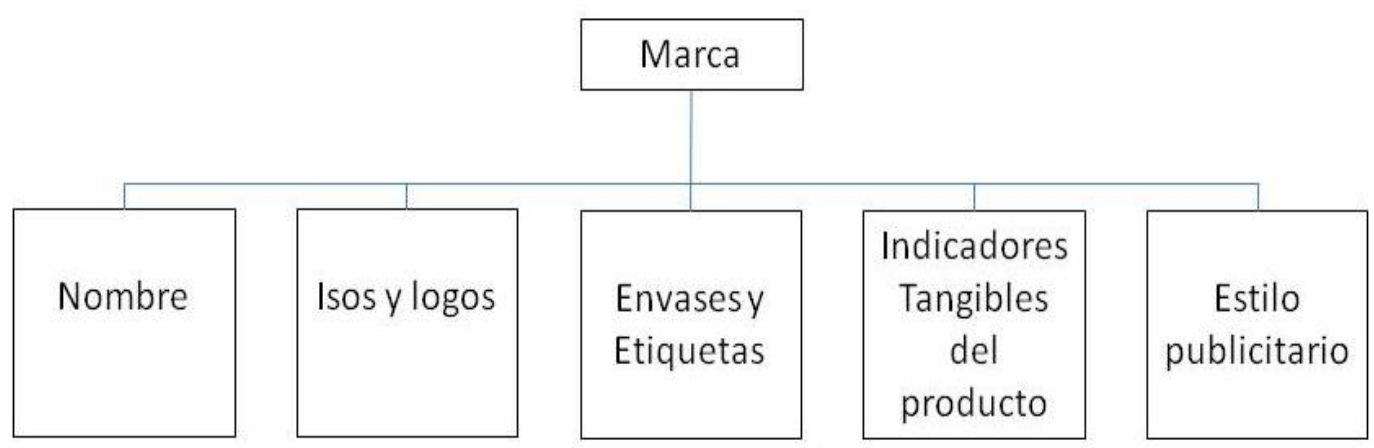

Alberto L. Wilensky, La promesa de la Marca (Grupo editorial Tem as, Argentina,1998 pág, 66)

Aplicando el cuadro anterior a la marca personal:

El nombre será, el cómo queremos diferenciarnos, cómo salir del anonimato y ser identificado, generalmente en el marketing personal se usa el nombre propio o un sobrenombre con el que se nos ha referido durante largo tiempo, pero tenemos que saber los elementos a usar cuando ponemos nuestro nombre, el primero es definir la personalidad, esta tiene que estar acorde con la del individuo a tratar, ya que será la que "crea una relación amor u odio e influye y se transfiere en la personalidad de los consumidores" $" 31$ (clientes). Por ejemplo un músico que se dedique a tocar música en español y ésta fuera su pasión, se vería contrariado si su nombre fuera en otros idiomas, o Michael Jordan que realizó su marca basada en su éxito deportivo se vería contradictorio vendiéndose como un académico o con libros de investigación, ésta es la importancia de tener una coherencia entre nombre, personalidad del individuo y la marca. El segundo punto son los valores que tendrá la marca y la persona es decir que formas de actuar que tiene el individuo que por ende tendrá la marca, tomando costumbres, modos de actuar y

\footnotetext{
30 Adaptación de Alberto L. Wilensky, La promesa de la Marca (Grupo editorial Temas , Argentina,1998 pág. 66)

31 Alberto L. Wilensky, La promesa de la marca (Grupo editorial Temas, 1998, pág. 140)
} 
sobretodo deberá ser socialmente aceptada. Y al final la identidad de la marca, que es "la promesa básica que la marca le hace al mercado" 32 y la diferencia del resto.

Después de tener el nombre se busca un Isotipo que es una imagen visual que permite describir un objeto o persona como la manzana de Apple, o la paloma de Nike y el Logotipo que es una palabra o frase que permiten describir tipográficamente un objeto o persona, como ejemplo las letras de Microsoft, o las letras cursivas de coca-cola. La importancia de éstos es que tendrán o no un recuerdo positivo o negativo en los clientes y logrará el poder identificar la marca en un futuro.

Después que tenemos el nombre y el isologo, debemos ver que envases y etiquetas va a tener nuestra marca, en el marketing personal cada uno de los individuos es su propio envase y como se vista, se arregle, se comporte y hable será su propia etiqueta, jamás veremos a un gerente de un banco atender a sus inversionistas con una nariz roja de payaso y tampoco contrataríamos a un payaso serio y de traje para una fiesta infantil, recordemos que en este mundo de reputación "como te ven te tratan".

Seguimos con los indicadores tangibles del producto. Estos son los aspectos físicos y funcionales que tiene cada uno, pero nosotros no veremos productos sino personas que aunque puedan considerarse como tal, existen ciertas diferencias y lo que le da la tangibilidad a la persona o su marca personal son los ideales compartidos con su entorno, la empatía hacia sus clientes, los valores que lo definen y el profesionalismo con el que trabaja, y éstos pueden ser más difíciles de medir ya que cada cliente tendrá su propia escala de medición según sus necesidades y alternativas de elección. Por ejemplo un abogado que se caracteriza por ganar sus casos de manera ilícita tiene su indicador de tangibilidad en el éxito y victorias obtenidas y le dará muchos clientes pero alguien con la moral muy alta jamás querrá contratarlo para que lo defienda y ahí es donde se ve la dificultad de medición a diferencia de Apple que sus indicadores de tangibilidad del producto

\footnotetext{
${ }^{32}$ Alberto L. Wilensky, La promesa de la marca (Grupo editorial Temas, 1998, pág. 133)
} 
son la calidad, innovación, prestigio, funcionalidad del producto entre otros y no cambian para unos y otros consumidores, aunque prefieran otras marcas.

Y para cerrar los elementos de la marca, tenemos que saber que estilo publicitario se usará, es decir cómo, dónde y cuándo se publicitará nuestra marca, ésto implica el saber a qué público se quiere llegar dependiendo del tipo de marca que manejemos, y puede ser por cualquier medio de comunicación siempre que sea el adecuado para cada caso, por ejemplo si un cirujano plástico exitoso quiere publicitarse, no puede hacerlo en una revista de supermercado popular por que ni es el target que busca, ni es el lugar para publicitarse, en cambio si el mismo cirujano se publicita en alguna fiesta privada con modelos de diferentes marcas de lencería será más probable que su número de clientes y su prestigio aumenten.

Tomando estos elementos se puede crear una marca y tomar los aspectos importantes para su desarrollo coherente y con la intención de hacerlo exitoso. Un ejemplo general es el caso del actor "Chabelo".

El actor y comediante Xavier López en México es quien porta la marca "Chabelo" con la cual durante más de tres generaciones ha actuado como un niño, jugando y cantando, en su programa "en familia con Chabelo" y

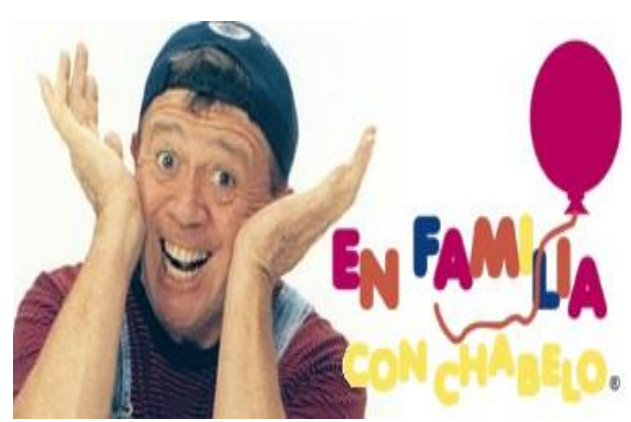
hoy a sus 76 años continúa con sus valores fundamentales de la niñez y la familia arraigados en su personalidad lo que logra una gran credibilidad y con su imagen de niño refuerza estos valores y esta marca.

"Chabelo" maneja un Isotipo que es su cara ya sea en persona o en dibujo animado y su logotipo es la frase "En familia con Chabelo" y esto ha sido un recuerdo positivo en las familias mexicanas por más de 30 años. 
Esta marca esta envasada bajo un overol, playera (remera), gorra, tenis (zapatillas) y etiquetada con una voz aguda con frases de niño y berrinches como tal, que corrobora la imagen de su marca y su packaging.

Los indicadores de tangibilidad para esta marca son la empatía con sus clientes en este caso sus fans, y seguidores, los ideales y valores que se asemejan a su público, y el profesionalismo que tiene por su trabajo que lo ha hecho ser único durante tantos años.

"Chabelo" utiliza la televisión abierta para publicitarse, en horarios familiares, las redes sociales, sitios web, pero lo más importante es el tiempo en que su trabajo ha sido la mayor publicidad, el estar de boca en boca a través de generaciones es lo que lo ha hecho un ícono Mexicano.

Así describiendo los elementos referidos anteriormente podemos ver que una marca que cumpla coherentemente con éstos y con la persona que va a portar la marca, puede lograr un gran éxito y también podemos reforzar la idea de que el marketing personal y la creación de marca no es una forma de cómo venderse al público solamente sino el hacer un proyecto de vida laboral, social y personal con el cual se esté satisfecho y cumpla los objetivos establecidos.

Cada individuo debe ser diferente, encantar y entusiasmar a sus clientes y ya que tenemos una marca lo que se busca es tener un posicionamiento en el entorno que se va a desenvolver la misma, mediante la lealtad y el liderazgo y es un trabajo dinámico durante todo el proyecto de vida. "El secreto del liderazgo es prestar atención y entregar el corazón a los detalles. La imagen que tienen los seguidores de los líderes no es el producto de una autoridad en torno a ellos sino de pequeños detalles de la vida cotidiana",33 esto hace referencia a lo que nos dará un liderazgo como marca y es el trabajo contínuo, los desarrollos estratégicos y cambios que vayamos haciendo en el camino, si logramos ser líderes en el entorno donde nos localicemos y mantener ese liderazgo, tendremos una lealtad y confianza de

\footnotetext{
${ }^{33}$ Debashis Chatterjee, El liderazgo consiente (Editorial Granica, España 2001)
} 
nuestros clientes, además si el cliente tiene confianza percibirá la calidad de la misma posicionándola aun más.

Para mantener la lealtad del cliente podemos basarnos en el círculo de lealtad de Christopher Lovelock y Jochen Wirtz que vemos a continuación:

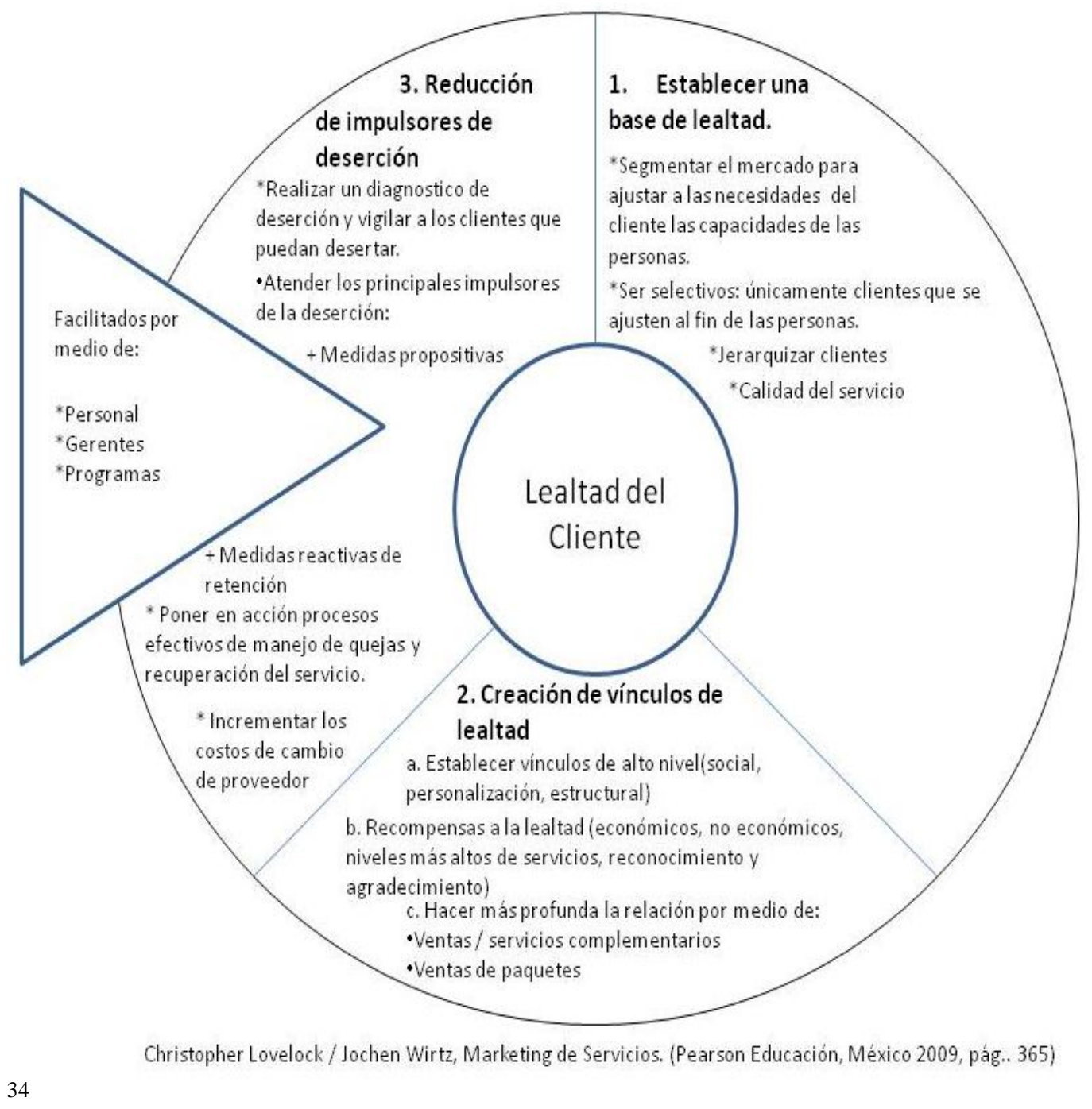

Tomemos sus tres puntos para la lealtad del cliente, establece en la base de la lealtad un acercamiento de persona-cliente basado en sus capacidades y habilidades siendo selectivos con los mismos, con calidad y jerarquías es decir la lealtad se ganará solamente en el entorno que nos desempeñemos, y la marca tiene

${ }^{34}$ Christopher Lovelock / Jochen Wirtz, Marketing de Servicios. (Pearson Educación, México 2009, pág.. 365) 
que cumplir esa necesidad de elección siendo la mejor alternativa para el cliente. Por ejemplo un político que quiere desempeñar un cargo en cierta provincia no debe poner más esfuerzo en provincias vecinas sino que debe estar con los ciudadanos de la provincia donde quiere ser electo y lograr empatía y profesionalismo que le denotará la calidad. Logrando esta elección se crea el lazo o la relación cliente-marca personal, y se empieza a crear el vínculo de lealtad, estos tienen que ser tomados en cuenta por la persona, cultivar esos lazos y ser recompensados. Hablando del mismo político cuando hace un meeting, conoce mucha gente, empieza a crearse el vínculo, si es capaz de recordar la mayoría de los nombres y en su siguiente meeting puede saludar a los votantes por el mismo, el vínculo se fortalecerá y se notará como una recompensa psicológica por estar ahí. Y termina con la reducción de deserción, en ésta se necesita un estudio del por qué está desertando el cliente y así tomar medidas para retener a los que valen la pena y dejar ir los que en un momento pueden ser un costo mayor, regresando al político que hizo ya su vínculo puede enterarse que cierto sector de la provincia está desertando, esto por la falta de servicios que existen ahí, el político dependiendo de la cantidad de votantes y la importancia del sector podría crear un acuerdo de que al ser electo arreglará directamente el problema, certificarlo ante un escribano para darle credibilidad y retener así a sus clientes o votantes y ganar su lealtad.

Teniendo estos conceptos llegamos al posicionamiento de la marca que es el "establecimiento de un lugar distintivo, en la mente de los clientes, con respecto a los atributos que poseen o no los productos de la competencia" ${ }^{35}$, es decir ya que la persona es vista como un líder, y se genera la lealtad, la persona es escogida y permite claramente que la persona esté por delante de las otras elecciones, así como construir para la persona un espacio para dar una ventaja diferencial. Regresando al político que se dió a conocer como un líder, creó la lealtad en ellos mediante sus estrategias de relaciones, vínculos y retención de votantes logra estar

${ }^{35}$ Christopher Lovelock / Jochen Wirtz, Marketing de Servicios. (Pearson Educación, México 2009, pág.. 630) 
por encima en el plano mental de los otros candidatos, es decir posicionándose mejor que su competencia, y al final obteniendo más votos.

Ya descritos estos elementos que forman el marketing personal y su finalidad, tenemos que conocer el cómo poder lograr esto, que herramienta se usa para poder cumplir nuestros objetivos, y la respuesta es la realización del plan de marketing enfocado a las personas o plan de marketing personal. 


\section{Plan de Marketing Personal}

Ya que pasamos y describimos las herramientas de creación de marca, su posicionamiento y su diferenciación pasamos al último punto de esta tesina que es el plan de marketing.

El plan de marketing es un "documento escrito que resume lo que el especialista de marketing ha aprendido sobre el mercado, que indica como la empresa pretende alcanzar sus objetivos de marketing y que facilita, dirige y coordina los esfuerzos de marketing." 36 . Cambiándolo al marketing personal dice como una persona quiere alcanzar sus objetivos profesionales y personales, coordinando las estrategias para facilitar un proyecto de vida. Este es necesario ya que permite tener una planificación acerca de las actividades que usaremos para cumplir los objetivos que deseamos de una manera más eficaz.

Para ayudarnos a describir un plan de marketing personal tomemos en cuenta estas tres preguntas ¿Dónde estamos?, ¿A dónde vamos? Y ¿A dónde queremos llegar?

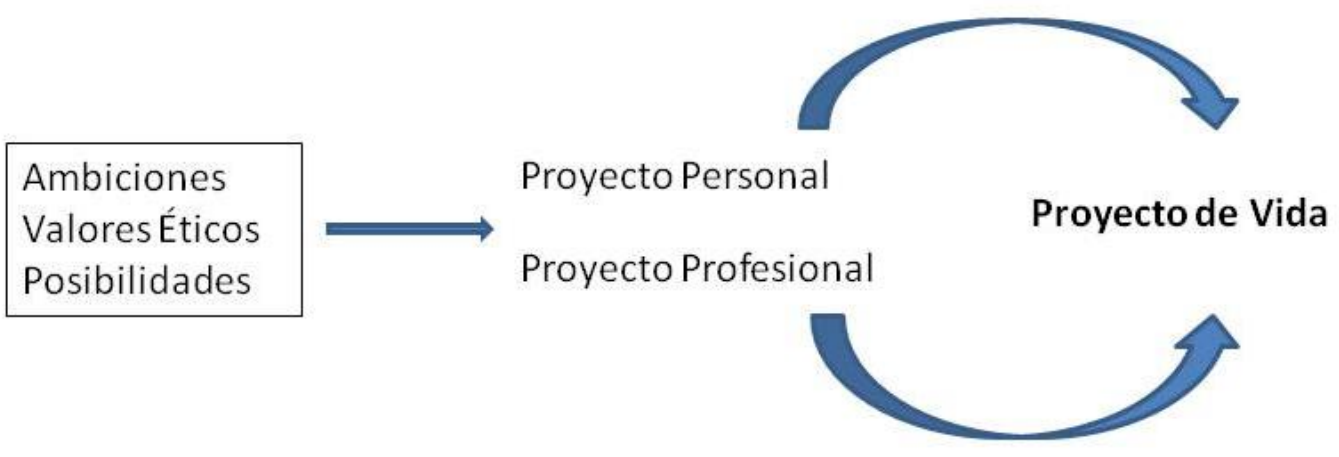

Manuel Schneer, Tu eres tu propia marca (Editorial Norma SA, Bogotá 2006 pág.. 26

\footnotetext{
${ }^{36}$ Philip Kotler y Kevin Lane Keller, Dirección de Marketing (Pearson Educación, México 2006, duodécima edición, pág. G6)

${ }^{37}$ Manuel Schneer, Tu eres tu propia marca (Editorial Norma SA, Bogotá 2006 pág. 26)
} 
Este cuadro nos da una visión de cómo responder las preguntas anteriores y alcanzar nuestros objetivos personales y proyecto de vida.

La pregunta ¿Dónde estamos? Se resuelve conociendo que ambiciones tenemos, es decir, cuales son las metas más altas a las que hoy en día se quiere llegar, qué valores éticos se tendrán en cuenta por la importancia de la coherencia entre la marca y la persona, y las posibilidades de cumplir estas metas mediante las herramientas personales, sociales, financieras, académicas y de conocimientos que se pueden utilizar para cumplir los objetivos.

Cuando se clarifica esto se puede definir donde se está parado el día de hoy, y se continúa con la pregunta ¿A dónde vamos?, esta respuesta es sencilla y se resuelve con un poco de introspección y reflexión personal, ya que es una reacción de saber el dónde se está, es el reflejo de la búsqueda del proyecto personal y profesional equilibrado y su importancia se debe a que es la etapa donde se puede pensar en que cambios hacer en las acciones que desarrollamos si la persona no se siente satisfecha con el camino al que se dirige o si cree que siguiendo ese camino no se completarán los objetivos propuestos.

Esto puede verse diariamente en uno mismo, la familia, los amigos y conocidos, que son trabajadores insatisfechos por desempeñarse en actividades que no les complace o que sus trabajos son tan demandantes que no les permiten darse el tiempo para la recreación o vida familiar, lo que provoca después de cierto tiempo una disminución en la eficiencia del mismo, y sin embargo se continúa en el mismo lugar por la creencia de no tener otras oportunidades o habilidades personales para otras actividades; o personas que no buscan realizarse profesionalmente por quedarse en casa o empresas familiares para continuar el proyecto personal de familia sintiéndose insatisfechos por no cumplir sus metas profesionales.

Conociendo a dónde se dirige se puede entonces saber si se quiere seguir ese camino o no, y a su vez contestar ¿A dónde queremos llegar?, la respuesta de ésta está dirigida al proyecto de vida, a un crecimiento integral de las personas, para 
que se puedan desarrollar al máximo las habilidades de los individuos y cumplir todos los objetivos personales.

Teniendo este análisis se puede seguir con el plan de marketing personal y sus contenidos se distribuyen en seis fases:

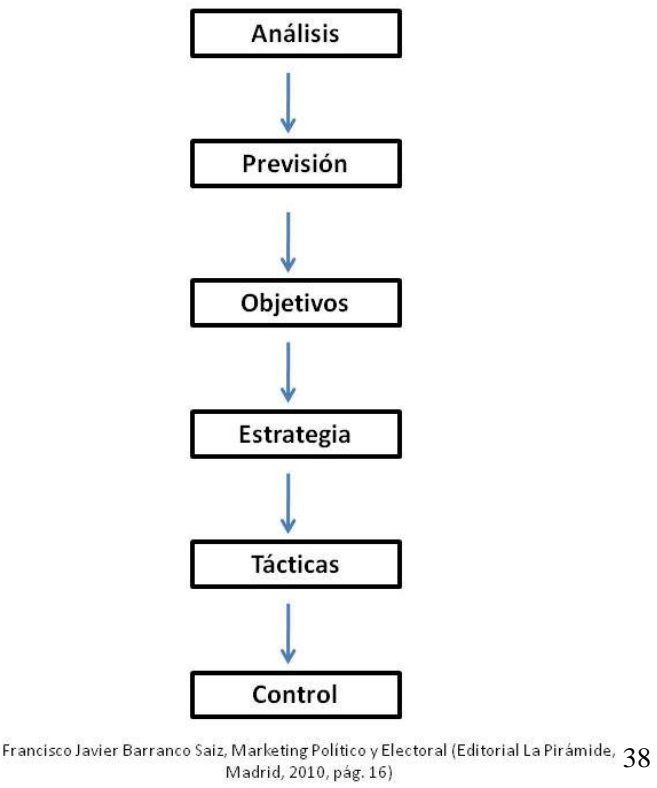

Estas fases se pueden relacionar con el siguiente cuadro:

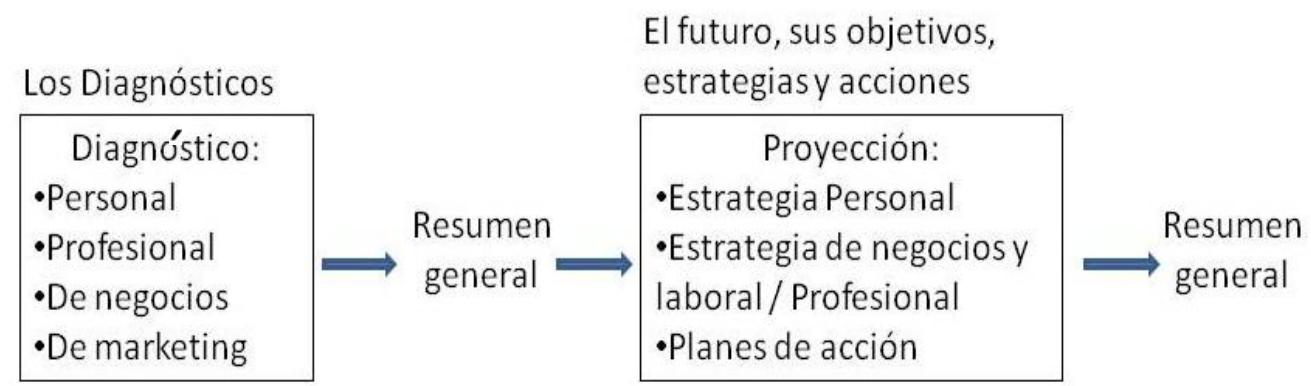

Manuel Scheneer, Tu eres tu propia marca, Marketing personal para un profesional (Editorial Norma, Bogotá, 2005 pág. 86)

En la fase de análisis se observará el diagnóstico, primero un diagnóstico personal, en donde la persona debe conocerse a sí misma, esto se logra mediante

${ }^{38}$ Francisco Javier Barranco Saiz, Marketing Político y Electoral (Editorial La Pirámide, Madrid, 2010, pág. 16)

${ }^{39}$ Manuel Scheneer, Tu eres tu propia marca, Marketing personal para un profesional (Editorial Norma, Bogotá, 2005 pág. 86) 
el ir indagando en uno mismo. Es decir qué se ha logrado en el ámbito personal y profesional, qué se quiere lograr y con quién se quiere lograr esto, es ver de dónde se parte, qué cualidades se tienen y qué relaciones se han obtenido. En el ámbito profesional se debe conocer las habilidades que tiene la persona, y es recomendable realizar una lista con habilidades, debilidades, logros, fracasos, cualidades y defectos, esta lista permite conocer en que entorno la persona tendrá mayor cualificación y se desempeñará mejor, ésto solo si ese entorno es el que sigue el proyecto de vida de la persona, en caso que no fuera así permite reconocer las debilidades para en un futuro tomar acciones y buscar una solución.

En la fase de previsión ya se debe conocer la situación, entonces se decidirá donde se quiere poner a trabajar la marca y la persona, es decir en que entorno se desarrollará, se identificará como se están cumpliendo las necesidades de elección de los clientes y como pudiese mejorar ese cumplimiento, para lograr posicionarse en el entorno. Con estos resultados se pondrá en marcha una herramienta básica en cualquier plan de marketing que es el análisis FODA, que es un análisis de Fortalezas y Debilidades internas de la persona, y Oportunidades y Amenazas externas que se puedan encontrar en el entorno donde se quiera desarrollar, el fin de este análisis es el usar la matriz FODA combinando las Fortalezas, Oportunidades, Debilidades y Amenazas para maximizar lo bueno y minimizar lo malo que pudiese tener la combinación entorno-persona para el desarrollo de propuestas de estrategias para el fortalecimiento de la persona y que logre cumplir sus objetivos. 


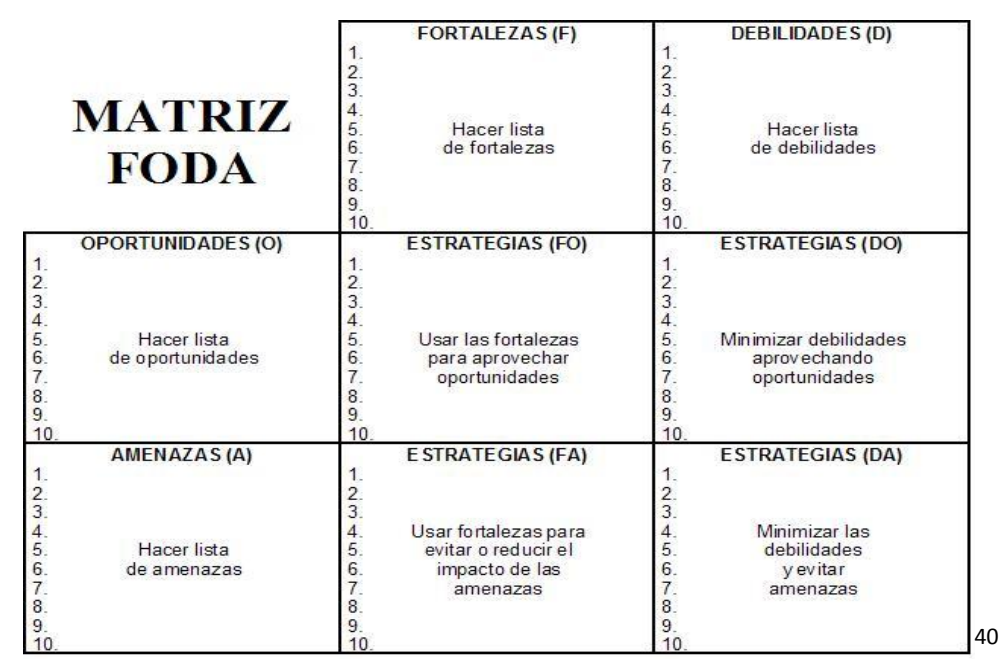

El análisis FODA no es algo que se realice de una vez y para siempre. Al contrario será un procedimiento que no termina nunca, que debe ser parte de la persona y su marca en este proceso dinámico necesario para su proyecto de vida.

En la fase de objetivos es donde se desarrollarán los objetivos estratégicos, estos deben se medibles para poder ser controlables. Son objetivos a corto o mediano plazo que sean de utilidad para cumplir el proyecto de vida de la persona. En esta etapa de los planes de marketing comerciales se pide el realizar la Misión, Visión y Objetivos estratégicos de la empresa, será igual para el marketing personal pero con las mismas diferencias que se han tomado en cuenta desde el inicio, la Misión será entonces el proyecto de vida, y el cómo se quiere lograr cumplir ese proyecto de vida, la Visión será la coherencia de la marca-persona-proyecto de vida, es decir cómo quiere ser vista la persona con su marca y cómo logrará ser vista, y los Objetivos estratégicos serán los puntos a corto, mediano y largo plazo, cuantificables y concretos, es decir las acciones que se quieren lograr realizar para conseguir cumplir con el proyecto de vida.

Teniendo este estudio y análisis se pasa a la fase de estrategias, esta es la etapa de planeación de las acciones para cumplir los objetivos, se planea la imagen con que se lanzará la marca personal y a qué entorno se dirigirá para lograr el

40 ING. MBA. Julio Carreto, Matriz FODA, (Blog Proceso Administrativo, http://uproadmon.blogspot.com/2007/02/matriz-foda.html) 
posicionamiento y cumplimiento del proyecto de vida que busca el marketing personal. Esto lo podemos visualizar en el siguiente cuadro:

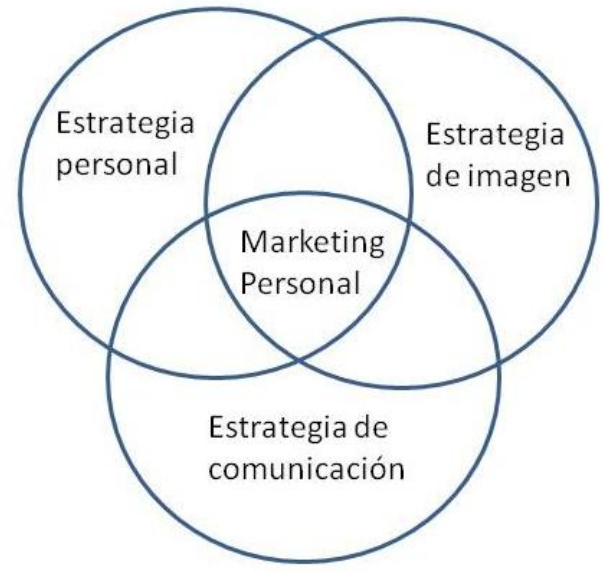

Donde la estrategia personal contempla los objetivos estratégicos a cumplir y el entorno donde se quiere desempeñar, es el diseño y planeación de la propuesta personal con los valores, personalidad y relación marca-persona; la estrategia de imagen es el cómo se necesita ser visto en el entorno, cómo será mi marca, qué isologotipo tendrá y cómo será el packaging, siempre con la coherencia necesaria para esto; y la estrategia de comunicación incluye todo el discurso de la persona, como se va a publicitar, que medios se usarán, como buscaremos el liderazgo y lealtad para el posicionamiento, y también siempre cuidando la coherencia marcapersona. Y con la conjunción de estas estrategias en caso de que al ponerlas en marcha resulten exitosas, se logra el posicionamiento de la persona con su marca que cumple y satisface su proyecto de vida.

Continúa la etapa de tácticas, en esta etapa lo que se busca es pasar la estrategia, es decir de la planeación a acciones concretas y medibles a corto plazo contestando las preguntas de ¿Qué se hará?, ¿Cuándo se hará?, ¿Quién lo hará?, ¿Cuánto costará?, aquí también entra el uso del marketing mix mediante el uso de las 4 p's. Producto, en este caso la persona es el producto que se ofrecerá al cliente. Precio, este implica un mayor esfuerzo ya que depende del valor personal y aspiracional de lo que la persona considere que vale su tiempo, habilidades y de lo que el cliente está dispuesto a pagar, un ejemplo de referencia es el ingeniero 
industrial especializado en cierta máquina, el cual cobra una fuerte suma por el mantenimiento en una empresa, cuando el dueño de la empresa pregunta el por qué cobra tanto ese ingeniero y no se tarda más de una hora mensual, la respuesta que recibe es sencilla, no hay otro que lo sepa hacer, así sucede en el marketing personal aunque el fin no es saber venderse, también se debe de aprender a hacerlo para poder dar un valor razonable a las actividades y servicios personales. Promoción en esta se utilizan distintos medios, pero lo que se busca en el marketing personal tiene como fin el ser conocido por una sola cosa, mostrar todos los logros que se han obtenido, contribuir activamente con el mercado, definir que es lo que se puede ofrecer al mercado, crear relaciones y vínculos, y demostrar excelencia, en fin, posicionar la marca personal. Plaza: que será el lugar en el que se desarrollará la persona, sus clientes, competidores, etc. Es el entorno que se ha descrito. Y así con la combinación de elementos, el estudio diagnóstico, la estrategia, las acciones y las herramientas del marketing mix se pueden tomar decisiones que serán medibles cualitativamente y cuantitativamente en la siguiente fase.

Control, en esta etapa es donde se comprueban los resultados obtenidos, es el final del plan de marketing personal y es en la que se dirá la realidad del esfuerzo realizado, es cuándo y dónde se pueden comparar los objetivos reales con los estratégicos, conocer si se cumplieron o como funcionaron, y tener en cuenta que tanto ha incrementado el posicionamiento de la marca personal y las posibilidades de cumplir el proyecto de vida.

El plan de marketing personal no funciona como algo inmóvil, se tiene que tomar en cuenta el cambio de vida o de motivaciones que es contínuo en las personas, así como las etapas personales desarrolladas a través de su crecimiento y cambios de entorno por lo cual es importante que se continúe verificando en la fase del control si es que se sigue manteniendo el proyecto de vida y que tanto están funcionando las estrategias usadas. 
Ahora se tendrá un caso de aplicación donde pondremos en marcha esta propuesta de plan enfocado a una persona y se desarrolla la búsqueda del posicionamiento de su marca personal. 


\section{Caso de Aplicación}

En este caso buscamos posicionar la marca "Rubí Díaz", pero describamos de dónde viene. Mariana Rubí Díaz Colorado es una artista dedicada al baile desde los nueve años y queriendo hacer de esto su forma de vida, se fue especializando cada vez más en su trabajo hasta llegar al día de hoy donde exclusivamente practica, baila, estudia y enseña danza árabe, logrando de esta su profesión y encaminando su proyecto de vida hacia esta danza.

Actualmente se desempeña como estudiante de último año en el profesorado en Danzas Árabes en la “Arabian Dance School” y cursa a la par el tercer año del profesorado en Danzas Árabes en la Escuela de "Danzas Árabes Saida", complementa sus estudios con Danza Hindu (Bollywood), Folcklore Árabe, Dabke, Jazz, Historia de la Danza Oriental y Ritmología Árabe, así como participa en diversas exposiciones, festivales y muestras de este arte en México y Argentina.

Su marca ha sido desde hace tiempo "Rubí Díaz" y es la que la ha caracterizado en México y en especial en San Luis Potosí, como una marca

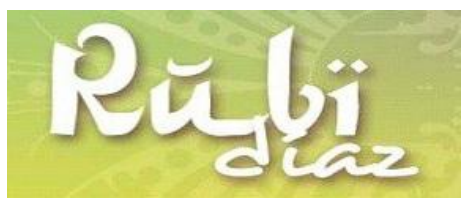
confiable con un estilo propio, único y de calidad.

Teniendo en cuenta que la marca ya está hecha y establecida, pero con la intención de darle un giro, pasamos a la primera fase del plan de marketing, el análisis, donde se responderán algunas preguntas de la marca-persona que servirán para el desarrollo del plan.

¿Qué ha logrado? "Debido al estudio logré un mayor reconocimiento nacional y sobre todo estatal como bailarina, también mucho más interés de la gente en lo que desempeño. He tenido mayor crecimiento en el arte y ahora soy más selectiva en las decisiones."

¿Qué quiere lograr? "Quiero una marca reconocida para mí y para la academia que quiero, no me interesa que sea reconocimiento internacional, si se dá, púes 
que padre, pero lo que me interesa es enseñar, y una academia propia que me deje un sueldo para vivir donde pueda desarrollar una línea de ropa de danza árabe y crear eventos con bailarines internacionales para fomentar más este arte en México.”

¿Qué tiene para lograrlo? "Casi un profesorado en danza árabe, también la atención de algunos bailarines talentosos, y el estilo reconocido en México, gente que me busca para que les enseñe, y el interés de seguir aprendiendo.”

¿Qué cualidades, defectos, habilidades, debilidades, tiene?

CUALIDADES/fortalezas

- Independencia personal ante la profesión.

- Sensibilidad

- Rítmica y estilo único

- Carisma y empatía

- Personalidad fuerte

\section{HABILIDADES/oportunidades}

- Los años bailando distintas cosas y estilos diferentes.

- Ser vista además de cómo bailarina como Lic. Ciencias de la Comunicación.

- No hay mucha competencia capacitada.

- Realizar un profesorado en danzas árabes fuera de mi país.

- Reconocimiento Estatal entre los que se dedican a la danza.

\section{DEFECTOS/debilidades}

- Imprudencia (decisiones/opiniones)

- Efusividad

- Agresividad en la forma que defiendo lo que quiero

- Dejar cosas sin terminar

- Inseguridad

DEBILIDADES/amenazas

- No haber ganado un concurso internacional de baile

- El baile no es considerado una profesión

- Económicas.

- Poco interés por la danza árabe en México

- Falta de apoyos para el arte 
Teniendo esta radiografía personal de la marca y la persona que tiene la marca, es decir de cómo ella misma se ve podemos empezar con la siguiente fase de previsión que es donde se definirá el dónde se quiere poner a trabajar la marca, para quienes y bajo que propuestas de estrategias.

Rubí Díaz se quiere posicionar en San Luis Potosí, San Luis Potosí, México. Por la zona centro de la ciudad en la colonia Himno Nacional, mediante una academia de danza árabe. El nicho al que se busca llegar en el estado es pequeño, sin embargo esto ayuda ya que el reconocimiento en este entorno se puede dar con mucha rapidez. La competencia que existe en el Mercado es de cuatro academias especializadas en danza árabe y los demás son cerca de 40 gimnasios con clase de todo tipo que van cambiando continuamente de maestros y estilos comunes y básicos y ningún maestro con experiencia internacional lo que permite posicionar con mayor facilidad la marca personal y lograr desarrollar un plus en ella. Los clientes que se buscan a diferencia de los competidores, son clientes que quieran hacer del arte su profesión, que busquen la danza como una forma de vida para que al final sean un reflejo de lealtad y posición de la marca. Esto es posible ya que en la ciudad existe gran cantidad de personas dedicadas al arte, que tienen que buscar en otras ciudades y países la forma de explotarlo y verlo como una profesión de vida, a los cuales se fidelizará con el fin de que lo logren sin necesidad de salir de su ciudad y si salen que sea por gusto propio.

Teniendo donde se quiere estar y a quien se quiere dirigir, hay que ver que propuestas de estrategias se podrían usar, esto se realiza mediante la matriz FODA. (Ver anexo 1).

Estas serán algunas propuestas de estrategias basadas en lo que se puede maximizar y que se debe minimizar, que se podrán utilizar para el cumplimiento de los planes que se propongan más adelante.

En la fase de objetivos tendremos:

Proyecto de vida: Hacer lo que me apasiona y lograr que la danza árabe sea mi profesión, donde "Rubí Díaz" tendrá un reconocimiento nacional que permita 
desarrollarme profesional, personal y familiarmente, basada en el esfuerzo, entrega y dedicación que me caracterizan.

Visión: Mediante una academia de danza árabe que cuente con reconocimiento nacional basado en el estilo único que diferencia a Rubí Díaz, causar en los clientes curiosidad y admiración por la danza, con el profesionalismo y calidad que distingue la misma.

Objetivos estratégicos:

- Posicionar la marca personal en el estado.

- Fidelizar clientes.

- Abrir una academia de danza árabe.

- Transferir el reconocimiento de la marca personal a una academia propia.

- Buscar reconocimiento y posicionamiento nacional.

Ya que tenemos los principales objetivos para lograr el proyecto de vida pasamos a la fase estratégica donde veremos qué medidas usar para cumplir los objetivos.

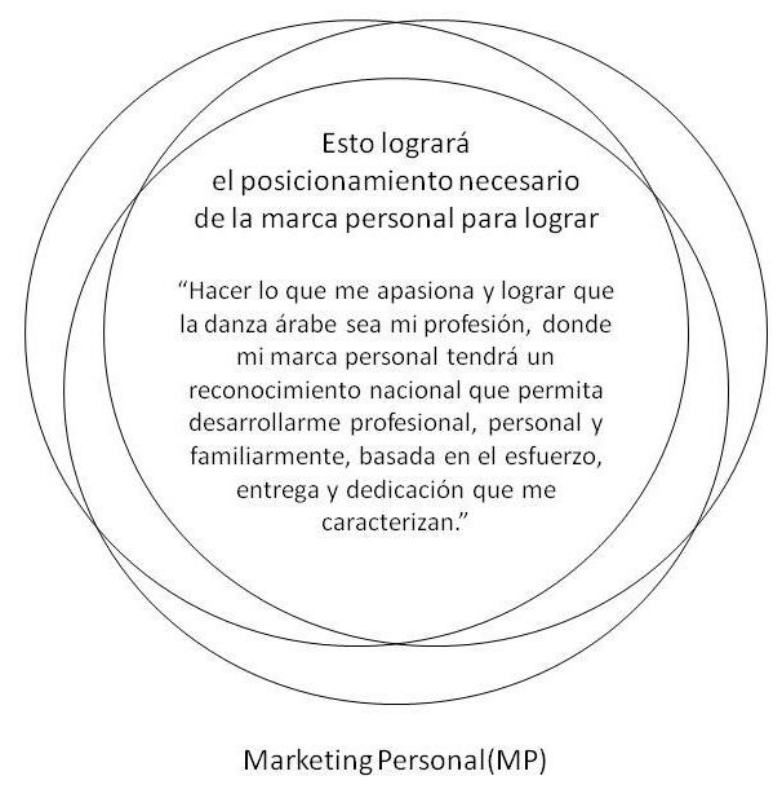




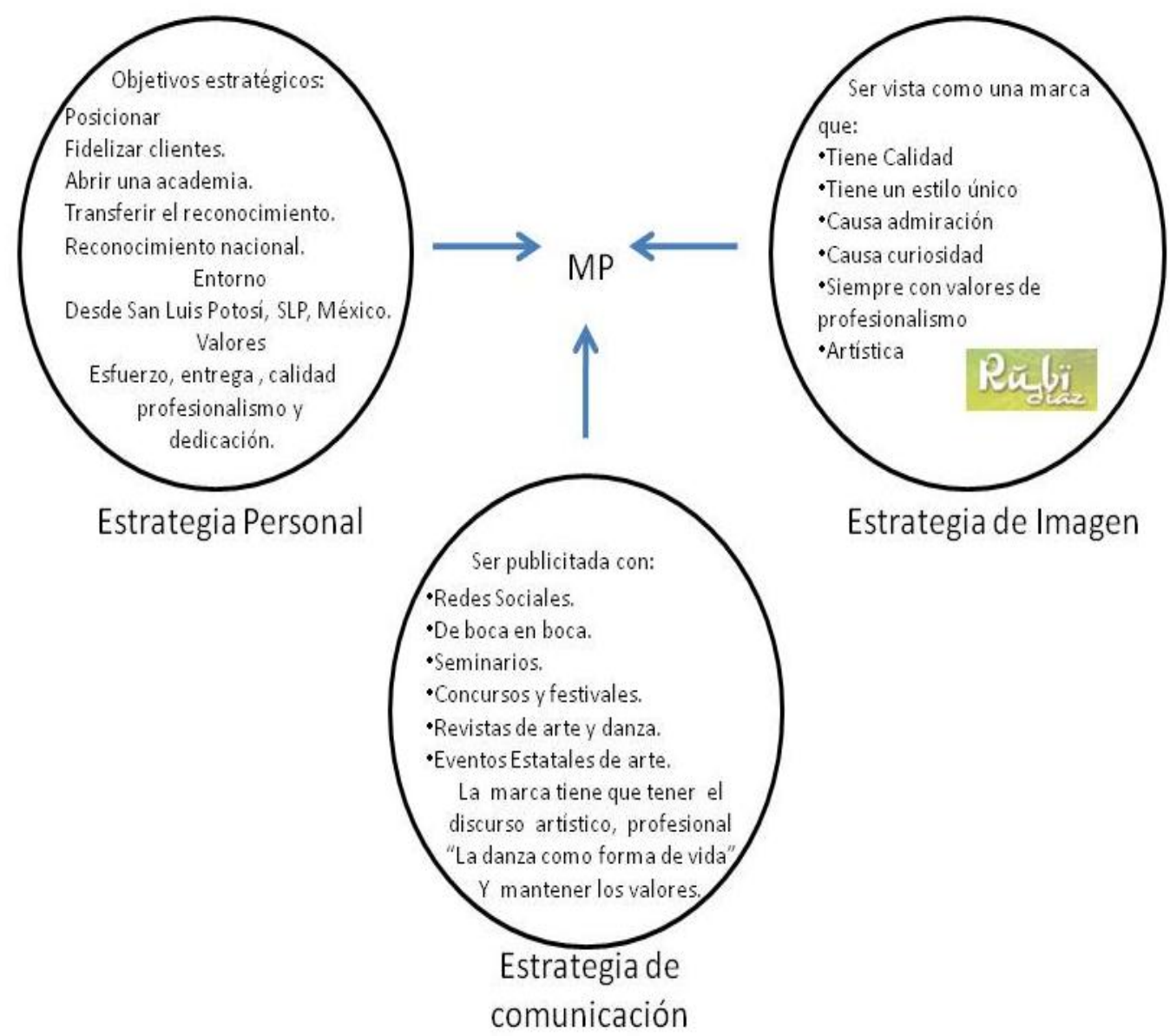

En la estrategia personal están los objetivos que se tienen que cumplir, en la ciudad de San Luis Potosí, SLP, México, y los valores que tiene la marca que no dejaremos pasar; la imagen que tiene actualmente se planea modificar para darle mayor énfasis en lo que quiere transmitir pero sin perderse la imagen que ya tiene cierto espacio mental en el nicho donde se desenvuelve; y la estrategia de comunicación es el discurso que tiene y que va a tener Mariana Rubí Díaz Colorado y la marca Rubí Díaz ya que la coherencia en esta parte es muy importante para darle la credibilidad de "La danza como forma de vida".

Continuamos con la parte de ejecución, es decir, vamos a ver qué haremos para cumplir estas estrategias, en esta etapa usaremos el marketing mix para usar las 4 p's y ver como las enfrentaremos directamente, esta etapa es la de tácticas. 
Definamos como usaremos las 4 p's; producto: en este caso Rubí Díaz es el producto que ofrecemos por lo que necesitamos seguir dándole el posicionamiento de la marca personal y el valor de calidad y profesionalismo; precio: usualmente se va con los del mercado, sin embargo sabiendo que lo que se paga en este arte es muy bajo se busca el que los clientes sientan esa diferenciación de obtener la marca personal, ésto mediante calidad y reconocimiento, y será por la actividad y el esfuerzo artístico que desarrolle; promoción: la marca personal debe ser conocida como una profesional en danza árabe (la danza como forma de vida); plaza: la marca personal se desarrollará en la ciudad de San Luis Potosí, SLP, México.

Las tácticas son:

A corto plazo:

- Posicionar la marca personal en el estado, mediante publicidad en:

○ Redes Sociales; facebook, youtube, twitter.

- De boca en boca, por la lealtad formada en los clientes al darles un producto diferenciado que es el estilo único.

- Seminarios, donde se dé algo novedoso que atraiga más clientes.

○ Concursos y festivales, participando activamente como jurado o asesora de los mismos, ya sean privados o públicos.

- Revistas de arte y danza.

- Eventos Estatales de arte, participando activamente para fomentar las relaciones para la red de trabajo artística.

- Modificar la imagen para darle mayor énfasis en los valores que se quieren transmitir pero sin cambiarla totalmente ya que tiene cierto espacio mental ganado en el nicho donde se desenvuelve.

A mediano plazo:

- Abrir una academia de danza árabe sumando la marca personal para transferir el reconocimiento a la misma.

- Fidelizar clientes mediante un estilo único de danza en la academia.

A largo plazo: 
- Realizar seminarios y eventos de árabe con invitados internacionales para lograr el reconocimiento nacional.

Teniendo las tácticas que se usarán tendremos la etapa de control donde verificaremos que resultados se han obtenido y como se ha posicionado $y$ mayormente supervisar que los objetivos y los tiempos se estén cumpliendo adecuadamente.

Actualmente está trabajando con la parte a corto plazo, Rubí Díaz sigue adquiriendo conocimientos en Buenos Aires, Argentina, ha participando en eventos que le dan mayor profesionalismo lo que influye en la calidad hacia los clientes. También en la elaboración de seminarios donde ha logrado posicionarse y causar admiración, tanto en sus clientes como en su competencia, y este posicionamiento que se está formando ha logrado su participación como jurado en concursos de árabe este año en la ciudad de San Luis Potosí, SLP. México. 


\section{Conclusión}

Para concluir con esta tesina nos enfocaremos en tres puntos esenciales:

El primero es el demostrar el marketing personal como una forma importante de tener un proyecto de vida, conforme va avanzando el mundo y el crecimiento poblacional, cada día es más complicado diferenciarse como persona, profesional, artista, o de cualquier modo que no siga una tendencia global o conjunta, sin embargo cada persona es única y puede, si se lo propone, tomar esa diferenciación que tiene para lograr cumplir sus objetivos personales. Estos objetivos no se forman con nada del otro mundo, es simplemente el contestarse a las preguntas ¿qué quiero hacer?, ¿cómo lo voy a hacer? y ¿qué tengo para lograrlo? y al realizarlo, además de que la persona será más eficiente en sus actividades laborales, también tendrá un crecimiento en sus relaciones personales y sociales, transformándolo, por ende, en una mejor persona. Actualmente, se tiene la tendencia del coaching personal que es precisamente la función de un coach que les enseñará a hacer marketing personal para la elaboración de su proyecto de vida, esto es por la importancia de esta modalidad de marketing en la vida diaria. En fin, el marketing personal lo podemos concluir como: el trabajar en nosotros mismos, para lograr esa relación de persona-deseos/sueños-realidad-valores que forman la personalidad de cada uno y explotarla al máximo para no ser un ente más en la vida, frustrado por no saber que quiere o hacia dónde va y convertirnos en los dueños de nuestra vida y nuestros actos.

El segundo punto es la diferenciación personal que queremos y tenemos como necesidad por ser seres humanos, que día a día buscamos desde los distintos entornos y roles que nos toca ocupar, el destacar ante los demás y no ser uno más, es la diferencia que señalaremos como nuestra marca personal y como dijimos, es como nos vamos a presentar ante el entorno, y es básica para poder desarrollarnos en un lugar especifico. Cada persona tiene nombre y apellido y así funciona nuestra marca personal es lo que va a representarnos y posicionarnos ante los objetivos que deseamos obtener, tiene nuestra personalidad e identidad en ella y es 
lo que nos va a quitar ese puesto de commodity ante las otras personas. Por esto es su importancia y si se trabaja será una herramienta que unificará y dará a conocer nuestra persona con lo que hagamos, dejando una huella en el mundo por más pequeña que sea pero siendo y haciendo historia donde otros pasarán desapercibidos.

Y el tercer punto es la planeación de cómo lograr lo anterior, cómo poder cumplir esas metas y objetivos que nos llevarán al éxito de nuestros sueños, a hacer ese proyecto de vida tan anhelado, esto podemos realizarlo usando el plan de marketing que precisamente será el plan de cómo lograremos desarrollar las estrategias que nos harán mejores personas, no buscar un trabajo, una venta, un puesto en algún lugar, sino que permita desarrollarnos como mejores personas, logrando una mejor calidad de vida. Dice Arthur Schopenhauer que "No hay ningún viento favorable para el que no sabe a qué puerto se dirige." y es exactamente lo que planteamos con esto, sabremos cómo vamos a llegar a dónde queremos ir, teniendo una guía para no perdernos en el camino y, si así fuera, poder encontrar el mejor camino de regreso a nuestro proyecto de vida.

Para cerrar esta tesina es preciso decir que cuando se logran unir estos tres puntos con coherencia, tendremos una capacidad de autoconocimiento que hará que se pueda cumplir cualquier proyecto de vida que tengamos, superar cualquier fracaso que nos aparezca en el camino y verlo como un obstáculo más que se puede vencer y se estará en posibilidad de conocer nuestras herramientas para ser cada día mejores personas en todos los ambientes en que nos desarrollemos. 


\begin{tabular}{|c|c|c|}
\hline MATRIZ & $\begin{array}{l}\text { Fortalezas } \\
\qquad \begin{array}{l}\text { 1. Independencia } \\
\text { (profesión/persona). } \\
\text { 2. Sensibilidad. } \\
\text { 3. Rítmica y estilo } \\
\text { único. } \\
\text { 4. Carisma y empatía. } \\
\text { 5. Personalidad fuerte y } \\
\text { única. }\end{array}\end{array}$ & $\begin{array}{l}\text { Debilidades } \\
\text { 1. Imprudencia } \\
\text { (decisiones/opiniones). } \\
\text { 2. Efusividad. } \\
\text { 3. Agresividad } \\
\text { (intolerancia en la } \\
\text { profesión). } \\
\text { 4. Dejar cosas sin } \\
\text { terminar. } \\
\text { 5. Inseguridad. }\end{array}$ \\
\hline Oportunidades & Estrategias (FO) & Estrategias (DO) \\
\hline $\begin{array}{l}\text { 1. Los años bailando } \\
\text { distintas cosas. } \\
\text { 2. Ser vista además de } \\
\text { cómo bailarina como } \\
\text { Lic. Ciencias de la } \\
\text { Comunicación. } \\
\text { 3. Realizar un } \\
\text { profesorado en } \\
\text { danzas árabes fuera } \\
\text { de mi país. } \\
\text { 4. No hay mucha } \\
\text { competencia } \\
\text { capacitada. } \\
\text { 5. Reconocimiento } \\
\text { Estatal entre los que } \\
\text { se dedican a la } \\
\text { danza. }\end{array}$ & $\begin{array}{l}\text { 1. Aprovechar las } \\
\text { técnicas de otros } \\
\text { estilos de baile y la } \\
\text { independencia } \\
\text { profesional para } \\
\text { hacer un estilo único. } \\
\text { 2. Tener la sensibilidad } \\
\text { para explotar al } \\
\text { máximo el estudio } \\
\text { fuera del país ante } \\
\text { los clientes y } \\
\text { fidelizarlos. } \\
\text { 3. Seguir estudiando y } \\
\text { conociendo para no } \\
\text { perder actualización } \\
\text { y calidad. }\end{array}$ & $\begin{array}{l}\text { 1. Buscar una forma de } \\
\text { incrementar la } \\
\text { confianza y seguridad } \\
\text { en la marca. } \\
\text { 2. Buscar un entorno que } \\
\text { use las relaciones y el } \\
\text { reconocimiento para } \\
\text { generar una red de } \\
\text { trabajo artístico. } \\
\text { 3. Buscar formas para no } \\
\text { dejar ningún proyecto } \\
\text { inconcluso. }\end{array}$ \\
\hline Amenazas & Estrategias (FA) & Estrategias (DA) \\
\hline $\begin{array}{l}\text { 1. Económicas } \\
\text { 2. No haber ganado un } \\
\text { concurso } \\
\text { internacional de } \\
\text { baile } \\
\text { 3. Poco interés por la } \\
\text { danza árabe en } \\
\text { México } \\
\text { 4. Falta de apoyos para } \\
\text { el arte } \\
\text { 5. El baile no es } \\
\text { considerada una } \\
\text { profesión }\end{array}$ & $\begin{array}{l}\text { 1. Buscar mediante la } \\
\text { personalidad y } \\
\text { carisma espacios } \\
\text { para que se tome en } \\
\text { cuenta la danza } \\
\text { como profesión. } \\
\text { 2. Lograr posicionarse } \\
\text { por un estilo único } \\
\text { aun sin haber ganado } \\
\text { ningún concurso } \\
\text { internacional. }\end{array}$ & $\begin{array}{l}\text { 1. Minimizar la } \\
\text { intolerancia profesional } \\
\text { con el fin de lograr } \\
\text { tener libertad } \\
\text { económica. } \\
\text { 2. Cuidar las decisiones } \\
\text { con respecto a los } \\
\text { clientes acerca de la } \\
\text { profesión ya que no es } \\
\text { reconocida como tal. }\end{array}$ \\
\hline
\end{tabular}




\section{Índice bibliográfico}

Libros:

- Barranco Saiz, Francisco Javier, Marketing Político y Electoral (Editorial La Pirámide, Madrid 2009)

- Burk Wood, Marian, The Marketing Plan: A handbook (Upper Saddle River, NJ Prentice Hall, 2003)

- Chatterjee, Debashis, El liderazgo consciente, un peregrinaje hacia el autocontrol (Ed. Granica 2001).

- Hatton, Angela, La guía definitiva del plan de marketing (Pearson Educación, Madrid 2000)

- Kotler, Philip y Lane Keller, Kevin, Dirección de Marketing (Pearson Educación, México 2006,)

- Lovelock, Christopher y Wirtz, Jochen, Marketing de Servicios (Pearson Educación, México 2009)

- Martínez Pandiani, Gustavo, Marketing Político campañas, medios y estrategias electorales. (Ugerman Editor 4ª edición 2007)

- Maslow, Abraham, The Developing Person through the Life Span. 1983.

- Maslow, Abraham, Una teoría sobre la motivación humana (pirámide de Maslow o teoría de las jerarquías de las necesidades humanas, 1943).

- Mehrabian y Russell, An approach to environmental Psychology(1974).

- Scheneer, Manuel, Tu eres tu propia marca, Marketing personal para un profesional (Editorial Norma, Bogotá 2005)

- Wilensky, Alberto L., La promesa de la marca (Grupo editorial Temas 1998)

Publicaciones web

- Antiguay, Lorena, Ensayo de El concepto de personalidad:Allport y Shelldon (Universidad de Santiago de Chile 2002. http://www.apsique.com/wiki/EnsayosPersonalidad) 
- Giménez, Gilberto, La Cultura como Identidad y la Identidad como Cultura. (SIC. CONACULTA. México, http://www.oei.es/cultura/diversidad_cultural.htm).

- Ministerio de Fomento de España, Elaboración de un análisis DAFO en organizaciones de transportes, (Edición Mayo 2005 http://www.fomento.es/nr/rdonlyres/286fb432-2d3c-4596-94b31b2d96af526d/19424/iva3.pdf)

- Rojas Rojas, Luis Enrique, Posicionamiento de marcas (ITESM, 17 de agosto de 2005, México, http://www.cem.itesm.mx/investigacion/transferencia/valormarca.htm)

Blogs

- Alcázar, Ricardo, Marketing Personal ( Aptitus El Blog de Recursos Humanos,15 de mayo de 2010, http://blog.aptitus.pe/bienestar-personal-yprofesional/744/)

- AMA, Committee on Definitions http://www.marketingpower.com

- Carreto, Julio ING. MBA., Matriz FODA, (Blog Proceso Administrativo, http://uproadmon.blogspot.com/2007/02/matriz-foda.html)

- Evans, J. Berman, B. (1987) Marketing Third Edition Traducción Libre por Ray Víctor con fines académicos (http://www.docstoc.com/docs/87177965/HISTORIA-DELMARKETING)

- Grotz, Sonia Marketing Personal... ¿Para qué? (Negocios - IDEA, http://www.ideared.org/contenido/289/marketing)

- Linares V., Ing. J. Luis, Concepto de marketing personal (Blog Marketeando http://www.marketeando.com/2009/09/concepto-marketingpersonal.html)

- Nebrija, Antonio de. Seis décadas avanzando y aprendiendo (marketing c.u. estema, 12 16/07) sustraído de S. Watson Dunn, American Marketing Association (http://reportesdemercadeo.blogspot.com/2011/05/amaasociacion-americana-de-marketing.html). 
- Pérez, Amadeo, Historia y teoría del Marketing (http://amadeo.obolog.com/historia-teoria-marketing-23017”, 17 de agosto del 2007, el blog de homero, http://amadeo.obolog.com/historia-teoriamarketing-23017)

- Pérez, Florentino Entrevista con el Presidente del FC Real Madrid. 2009 (sustraído por PS. Fernando Rosario http://www.slideshare.net/ferospe9/marketing-personal-8087869).

- Traducción de Bartels, F.E.Clark de 1988, pp. 149-150,(sustraído de Amadeo Pérez, Historia y teoría del Marketing, http://amadeo.obolog.com/historia-teoria-marketing-23017). 
"Declaro bajo juramento que esta tesis fue elaborada por mí, que no utilicé ningún otro material que no haya dado a conocer en las referencias y que no utilicé frases o párrafo de otros autores, que este trabajo de tesis nunca ha sido presentado ante un comité de evaluación de tesis y que no transgreda derechos de terceros." 